\title{
A New Form of Leukoencephalopathy with Calcifications and Cysts with Nonrecessive Inheritance and Absence of Gadolinium Enhancement
}

\author{
Pierre Labauge $^{a} \quad$ Eric Berger $^{b}$ Eloi Magnin ${ }^{b}$ Lucien Rumbach ${ }^{b} \quad$ Manuela Mine ${ }^{c}$ \\ Dimitri Renard ${ }^{a}$

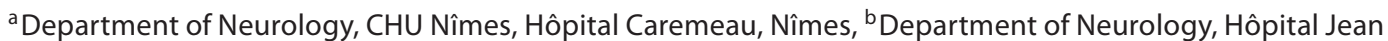 \\ Minjoz, CHU de Besançon, Besançon, and 'Laboratoire de Génétique, Hôpital Lariboisiere, Paris, France
}

Dear Sir,

A 37-year-old patient with tobacco as the only vascular risk factor presented with recent progressive attention deficit. Clinical examination showed generalized hyperreflexia and bilateral Babinski sign. Head circumference was $53 \mathrm{~cm}$. Neuropsychological testing confirmed executive dysfunction associated with slight memory loss. Brain CT showed extensive frontal and parietal white matter changes together with some small juxtacortical calcifications (fig. 1). MRI confirmed extensive frontal and parietal leukoencephalopathy and juxtacortical calcifications, and revealed multiple small cysts inside the areas of white matter changes, respecting the basal ganglia (fig. 1). There was no gadolinium enhancement. $\mathrm{T}_{2}{ }^{*}$ sequences did not find any microbleeds. CSF analysis was strictly normal. Ophthalmologic examination showed no abnormalities. Routine blood analyses were normal, and serological test for HIV was negative. A comprehensive research of metabolic causes of leukodystrophy (arylsulfatase A, galactocerebrosidase, very long chain fatty acids, phytanic acid levels) was negative. Genetic analyses for NOTCH 3 (in search for CADASIL), TREX1, EIF2B2 and EIF2B5 (for vanishing white matter syndrome) were negative.

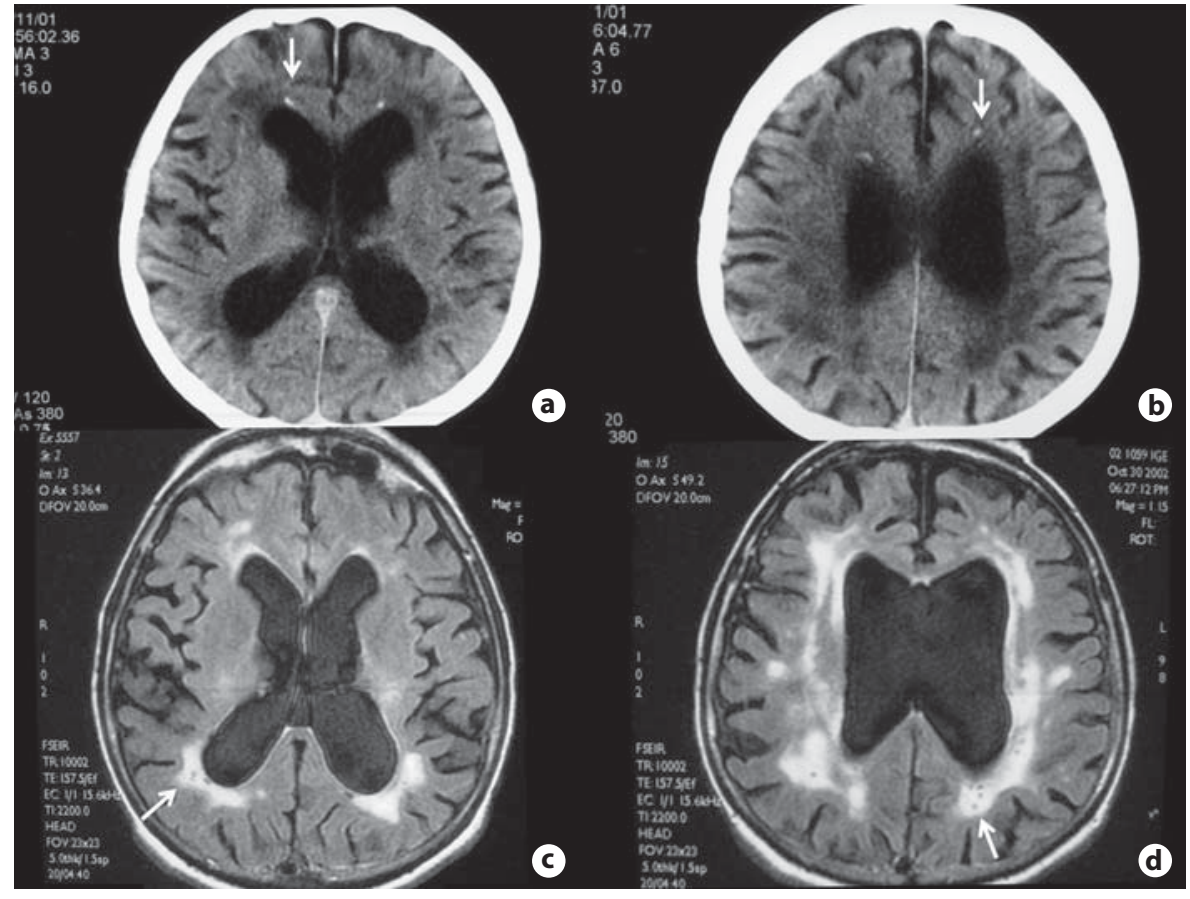

Fig. 1. Index case neuroradiological examination: a Brain CT scan: hypodensities of the white matter with small size calcifications (arrow). b-d $\mathrm{T}_{2}$ MRI examination: hyperintensities within the demyelinating aspect of the white matter on T2 2nd echo sequence (b, c, arrow) seen as hypointensities on Flair sequences (d, arrow).

\section{KARGER}

Fax +41 613061234 E-Mail karger@karger.ch www.karger.com
(C) 2012 S. Karger AG, Base 0014-3022/12/0673-0151\$38.00/0 www.karger.com/ene
Pierre Labauge, $\mathrm{MD}, \mathrm{PhD}$

Department of Neurology, CHU Nîmes

Hôpital Caremeau, Place du Pr Debré

FR-30029 Nîmes Cedex 4 (France)

Tel. +33466 6832 61, E-Mail labauge@yahoo.fr 

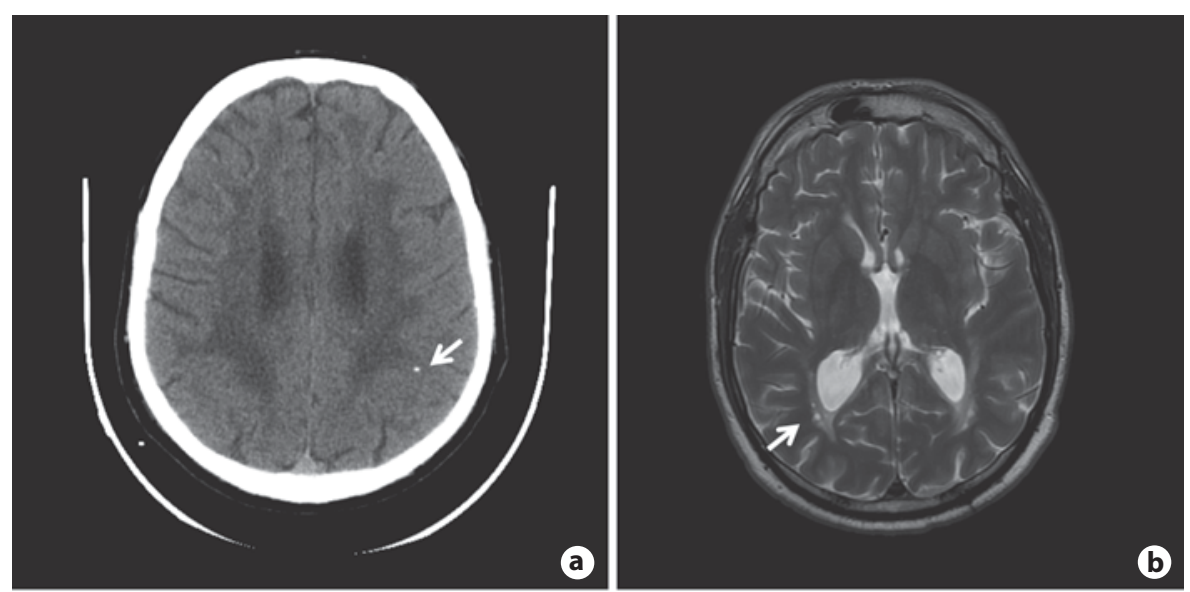

Fig. 2. Index case's mother: CT scan (a, b) and MR examination (c, d). a, b Small size of calcifications within the white matter hypodensities (arrow). c, d Flair sequences: cystic aspect seen as hypointensities (arrow) in the extensive demyelinating area.
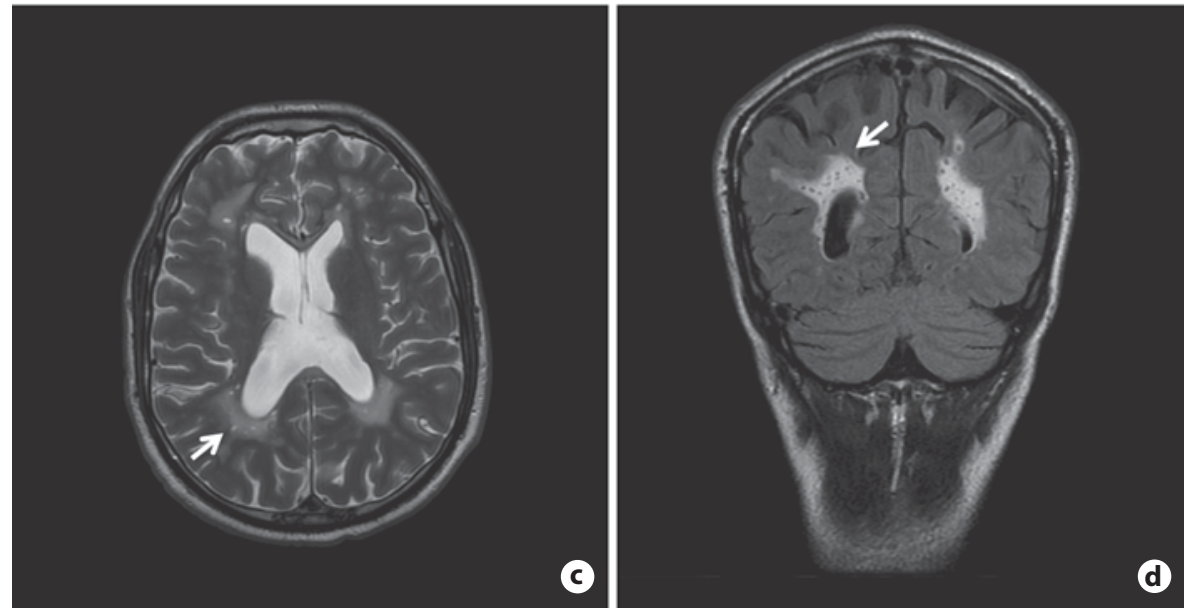

The mother of the patient, without medical history or vascular risk factors, died bedridden at the age of 63 after 5 years of progressive cognitive dysfunction and gait dysfunction. Brain CT, at the age of 60 , showed extensive frontal and parietal white matter changes as seen in her son, associated with multiple periventricular small calcifications (fig. 2). MRI confirmed extensive leukoencephalopathy and showed, again like her son, multiple small cysts inside the areas of white matter changes, respecting the basal ganglia. Gadolinium enhancement was absent.

All four (asymptomatic) brothers and the only (also asymptomatic) sister of the index case had normal cerebral MRI. Clinical examination in all these relatives was normal.

\section{Discussion}

Asymmetric calcifications, diffuse white matter changes, parenchymal brain cysts, gadolinium enhancement, are the hallmarks of leukoencephalopathy with calcifications and cysts (LCC) [1-4]. The mechanism is supposed to be an obliterative cerebral microangiopathy leading to disruption of the blood brain barrier, necrosis, gliosis, gradual formation of cysts [5]. Occurrence of additional symptoms (i.e. retinal telangiectasias, sparse hair, dysplastic nails, skeletal changes, hematologic abnormalities) leads to the diagnosis of cerebroretinal microangiopathy with calcifications and cysts (CRMCC), formerly called the Coats plus syndrome (5). Recent evidence suggests that CRMCC and LCC represent the same clinical entity with a common primary pathogenesis leading to a small vessel obliterative microangiopathy $[4,5]$. In earlier reported cases of LCC and CRMCC, the occurrence of affected siblings and consanguinity in parents, strongly suggested an autosomal recessive inheritance. Radiological abnormalities (i.e. white matter involvement, calcifications deposits, and cystic forma- tion) suggest a CRMCC diagnosis in our family [5], although dominant inheritance, normal ophthalmological examination, absence of gadolinium enhancement, small size calcifications without mass effect, and absence of edema were not in favor of CRMCC [5]. Other autosomal-dominant vascular leukodystrophies, such as cerebral autosomal-dominant arteriopathy with subcortical infarcts and leukoencephalopathy (CADASIL) and autosomaldominant retinal vasculopathy with cerebral leukodystrophy [6] were eliminated in our family by absence of mutation in NOTCH3 and TREX1 [6] genes.

The presence of leukoencephalopathy and small punctuate calcifications can be seen in the Aicardi-Goutieres syndrome. However, early age symptom onset, recessive inheritance, and persistent CSF lymphocytosis (all typically seen in the Aicardi-Goutieres syndrome) lacked in our patient and his mother. In addition, this diagnosis was excluded by the absence of TREX 1 gene mutation [7]. 
The observed parenchymal brain cysts could also suggest widening of VirchowRobin spaces [8]. In contrast, these latter are not associated with leukoencephalopathy and calcifications [8].

MR features are characterized in our report by a cystic aspect and not a radial disposition as usually seen in typical VirchowRobin spaces dilatations. This regular aspect could suggest an increasing fluid surrounding the arterioles and venules of the brain parenchyma rather a de novo cavitating process [8]. In addition, developmental dilatation of Virchow-Robin spaces with white matter abnormalities has been described in children and familial forms [8].

Our report suggests a new phenotype of LCC based on an autosomal dominant inheritance (or maternal transmission), with leukoencephalopathy, small-sized calcifications and absence of gadolinium enhancement.

\section{Acknowledgement}

The authors thank Professor Elisabeth Tournier Lasserve (INSERM U 740, Paris) for the search of NOTCH3 and TREX1 gene mutations.

\section{Disclosure Statement}

The authors did not report any conflict of interest.

\section{References}

1 Labrune P, Lacroix C, Goutieres F, et al: Extensive brain calcifications, leukodystrophy, and formation of parenchymal cysts: a new progressive disorder due to diffuse cerebral microangiopathy. Neurology 1996;46:12971301.

-2 Nagae-Poetscher LMG, Philippart M, Rosemberg S, et al: Leukoencephalopathy, cerebral calcifications, and cysts: new observations. Neurology 2004;62:1206-1209.

-3 Marelli C, Savoiardo M, Fini N, et al: Late presentation of leucoencephalopathy with calcifications and cysts: report of two cases. J Neurol Neurosurg Psychiatry 2008;79: 1303-1304.

4 Kleinschmidt-De Masters BK, Cummings TJ, Hulette CM, Morgenlander JC, Corboy JR: Adult cases of leukoencephalopathy, cerebral calcifications, and cysts: expanding the spectrum of the disorder. J Neuropathol Exp Neurol 2009;68:432-439.

5 Briggs TA, Abdel-Salam GMH, Balicki M, et al: Cerebroretinal microangiopathy with calcifications and cysts (CRMCC). Am J Med Genet 2008;146A:182-190.
6 Richards A, van den Maagdenberg AMJM, Jen JC, et al: C-terminal truncations in human $3^{\prime}-5^{\prime}$ DNA exonuclease TREX1 cause autosomal dominant retinal vasculopathy with cerebral leukodystrophy. Nat Genet 2007;39:1068-1067.

7 Crow YJ, Leitch A, Hayward BE, et al: Mutations in genes encoding ribonuclease $\mathrm{H}_{2}$ subunits cause Aicardi-Goutieres syndrome and mimic congenital viral brain infection. Nat Genet 2006;38:910-916.

-8 Bruna A-L, Martins I, Husson B, Landrieu P. Developmental dilatation of Virchow-Robin spaces: a genetic disorder? Pediatr Neurol 2009;41:275-280. 